\title{
Health Behaviour among Nurses Working in Public Hospitals in Kakamega County, Kenya
}

\author{
Mchidi Kiguhe Nebert, ${ }^{1}$ B. M. Okello Agina, ${ }^{2}$ and Yitambe Andre ${ }^{3}$ \\ ${ }^{1}$ Department of Community Health, School of Public Health, Kenyatta University, GPO 43844-00100, Nairobi, Kenya \\ ${ }^{2}$ School of Medicine, Kenyatta University, GPO 43844-00100, Nairobi, Kenya \\ ${ }^{3}$ Department of Health Management and Informatics, School of Public Health, Kenyatta University, GPO 43844-00100, Nairobi, Kenya
}

Correspondence should be addressed to Mchidi Kiguhe Nebert; nebertnelly@gmail.com

Received 27 July 2017; Accepted 31 October 2017; Published 31 December 2017

Academic Editor: Lesley Wilkes

Copyright (c) 2017 Mchidi Kiguhe Nebert et al. This is an open access article distributed under the Creative Commons Attribution License, which permits unrestricted use, distribution, and reproduction in any medium, provided the original work is properly cited.

\begin{abstract}
Health behaviour refers to actions undertaken by a person who perceives self to be ill for the purpose of finding an appropriate remedy. Nurses as gate keepers of health are expected to seek formal treatment when they are taken ill because this is what they teach their patients. Nurses' working conditions all over the world are described as squalid with long working hours and workload. This scenario predisposes them to occupational health hazards and at the same time denies them time for self-care. Although nurses are knowledgeable about disease and its treatment and have access to health care, they engage in self-treatment in contrast to what they teach patients. Health behaviour among nurses in Kakamega County was investigated using a cross-sectional design. Data was collected using self-administered questionnaires and subjected to bivariate and logistic regression analyses. The study found that health behaviour of nurses in Kakamega County is below expectation, as 33\% $(n=61)$ engaged in voluntary screening services. Further, 34.8\% $(n=65)$ said that their health would improve if they engaged in health promotion activities. The study recommends empowering nurses to engage in positive health behaviour through education. The county should also provide affordable screening services to its nurses.
\end{abstract}

\section{Background}

Nurses are an important resource for health. They have been cited as the backbone of health care provision due to their numerical strength in any health setting and being the most trusted profession among patients makes them ideal patient educators $[1,2]$. In order to be realistic in their health education and patient expectations, nurses must lead from the front by doing as they expect of their patients by engaging in positive health behaviour [3]. Health behaviour refers to actions of individuals aimed at detecting or preventing disease and improving their well-being [4]. Due to endemic shortages of health care providers all over the world, nurses are and will continue to be exposed to risks that predispose them to poor health as a result of increased workloads and long working hours that lead to burnout [5-8]. These situations limit their ability to achieve a work-life balance $[9,10]$. Nurses lack self-care discipline and engage in poor feeding habits and are burdened with noncommunicable diseases, circumstances that embarrass their statures as role models to their patients [11]. Nurses, like doctors, think that they are omnipotent and invisible, but there is increased morbidity among them due to the demanding nature of their work [12-17].

An Israeli study found that although doctors had strong belief in screening tests, only $27.5 \%$ of the respondents had undergone the tests, with $55.6 \%$ blaming it on lack of time [18]. Further, a Baltimore study found more than half of the participants as not having a regular meal schedule, leading to poor eating habits and obesity [19]. A Jordanian study found cultural beliefs as significant in determining the practice of self-breast exam for cancer screening among female nurses. A Norwegian study found that physicians were reluctant to attend screening programs due to forgetfulness or lack of time or due to the belief that they knew their own health to the extent that they thought they were at 
low risk for disease [5], factors that are cross-cutting in medical profession. Medicine has the professional culture of discomfort in seeking help [20,21]. Evidence shows that consultations that do not follow laid down protocols are rampant within the medical profession [22]. This unfortunate scenario has been attributed to perceived trust one has in the physician they choose for fear of confidentiality breach if they follow laid down protocols [16, 23]. Confidentiality dilemma reinforces what Wallace et al. [20] call "a conspiracy of silence" within the profession and contributes to negative health behaviour. Because health providers determine the confidentiality of health information they receive regarding patients, lack of trust in the confidentiality of the information nurses share with their peers regarding their health may be a barrier to health care seeking [24]. In Kenya, Taegtmeyer et al. [25] found that health care providers who had had a needle stick injury did not seek treatment because of the fear of HIV testing.

\section{Problem Statement}

In Kakamega County, anecdotal evidence suggests that the work load is very high, with many nurses reporting to work while sick. For example, the paediatric ward with a bed capacity of 34 usually has two nurses working on a shift. The county is the second populous county in Kenya, yet its nurse patient ratio of $34.87: 100,000$ is below the national average of $51.5: 100,000$. The most populous county, Nairobi, with double the population, has a nurse patient ratio of $88.74: 100,000$ [26]. This means that the nurse in Kakamega County has a lot of work pressure to meet patient health care needs, a situation that could compromise not only the nurses' health but also the health of the patients they take care of. From this background, there is need to investigate health behaviour of the nurses and generate information about them, an area that has not been studied in Kenya.

\section{Specific Objectives}

The objectives of this paper are listed as follows:

(1) To identify the predisposing factors influencing health behaviour of nurses in Kakamega County

(2) To determine the enabling factors influencing health behaviour of nurses in Kakamega County

(3) To investigate the need factors that shape health behaviour of nurses in Kakamega County

\section{Materials and Methods}

The study was conducted at the Kakamega County in Western Kenya. Kakamega County has 1 county referral hospital, 4 county hospitals, 7 subcounty hospitals, 34 health centers, and 86 dispensaries run by the government and several health facilities run by faith-based organizations and nongovernmental organizations. Within the county, nurses working in select public health facilities were selected. Specifically, the health facilities were 4 subcounty hospitals, 2 county hospitals, and 1 county referral hospital as listed in Table 1.
TABLE 1: Distribution of nurses in the selected facilities in Kakamega County (source, County Chief Officer of Health, 2013).

\begin{tabular}{|c|c|c|}
\hline District & Name of facility & $\begin{array}{c}\text { Number of } \\
\text { nurses }\end{array}$ \\
\hline $\begin{array}{l}\text { Kakamega } \\
\text { central }\end{array}$ & $\begin{array}{l}\text { Kakamega County } \\
\text { Referral Hospital }\end{array}$ & 241 \\
\hline Malava & $\begin{array}{c}\text { Malava } \\
\text { Sub-County } \\
\text { Hospital }\end{array}$ & 31 \\
\hline \multirow[b]{2}{*}{ Butere/Mumias } & $\begin{array}{c}\text { Butere Sub-County } \\
\text { Hospital }\end{array}$ & 31 \\
\hline & $\begin{array}{l}\text { Matungu } \\
\text { Sub-County } \\
\text { Hospital }\end{array}$ & 25 \\
\hline Lugari & $\begin{array}{c}\text { Lumakanda } \\
\text { County Hospital }\end{array}$ & 25 \\
\hline Likuyani & $\begin{array}{c}\text { Likuyani County } \\
\text { Hospital }\end{array}$ & 17 \\
\hline \multirow[t]{2}{*}{ Ikolomani } & $\begin{array}{c}\text { Iguhu Sub-County } \\
\text { Hospital }\end{array}$ & 16 \\
\hline & & 386 \\
\hline
\end{tabular}

The sample size was 187 nurses, and respondents were selected using simple random sampling technique. Data was collected using self-administered questionnaires using adaptations from a questionnaire used by Chen et al. [27]. Need factors were assessed using modifications of the SF-12v2 [28]. Ethical clearance was obtained from Kenyatta University Ethics Review Committee and a permit to carry out the study was obtained from the National Council for Science, Technology and Innovation.

Univariate analysis was used to describe the distribution of each of the variables. Bivariate analysis was used to investigate the difference between health behaviour and the predisposing, enabling, and need factors. Level of significance was set at $p \leq 0.05$ ( $95 \%$ confidence interval).

\section{Results and Discussion}

5.1. Predisposing Factors Influencing Health Behaviour. The majority belonged to age bracket of 30-39 years; the modal age was 40 years, while the median and mean age was 41 years, respectively. As shown in Table 2, majority of the respondents were female Protestants and had Kenya Registered Community Health Nurses (KRCHN) diploma as highest level of nursing qualification. The majority of the respondents were married, reported moderate support from supervisors, and had worked as nurses for more than 10 years.

5.2. Enabling Factors Influencing Health Behaviour. As shown in Table 3, the majority of the nurses said that work load was very high and they worked for 40-50 hours a week. Although the majority of the respondents said that they would prefer to be treated in the facility they worked in, they expressed dissatisfaction with both the quality of and access to health services available to them in the county. The most common health insurance cover possessed by the respondents was 
TABLE 2: Univariate analysis of predisposing factors that influence health behaviour.

\begin{tabular}{|c|c|c|}
\hline Characteristics & $\begin{array}{c}\text { Frequency } \\
(n)\end{array}$ & Percent \\
\hline \multicolumn{3}{|l|}{ Age (years) } \\
\hline Below 30 & 24 & 12.8 \\
\hline $30-39$ & 55 & 29.4 \\
\hline $40-49$ & 54 & 28.9 \\
\hline 50 and above & 54 & 28.9 \\
\hline Total & 187 & 100.0 \\
\hline \multicolumn{3}{|l|}{ Gender } \\
\hline Male & 64 & 34.2 \\
\hline Female & 123 & 65.8 \\
\hline Total & 187 & 100.0 \\
\hline \multicolumn{3}{|l|}{ Marital status } \\
\hline Married & 143 & 76.5 \\
\hline Single & 30 & 16.0 \\
\hline Separated/widowed & 14 & 8.5 \\
\hline Total & 187 & 100.0 \\
\hline \multicolumn{3}{|l|}{ Religion } \\
\hline Protestant & 147 & 78.6 \\
\hline Muslim & 2 & 1.1 \\
\hline Catholic & 38 & 20.3 \\
\hline Total & 187 & 100.0 \\
\hline \multicolumn{3}{|l|}{$\begin{array}{l}\text { Highest level of nursing } \\
\text { qualification }\end{array}$} \\
\hline Postgraduate level & 5 & 2.7 \\
\hline $\mathrm{BScN}$ & 26 & 13.9 \\
\hline Higher diploma in nursing & 13 & 7.0 \\
\hline KRCHN (diploma in Nursing) & 105 & 56.1 \\
\hline ECN (certificate in Nursing) & 32 & 17.1 \\
\hline KRN/M (registered midwife) & 6 & 3.2 \\
\hline Total & 187 & 100.0 \\
\hline \multicolumn{3}{|l|}{$\begin{array}{l}\text { Years nurses have worked in the } \\
\text { county }\end{array}$} \\
\hline 6 months-1 year & 21 & 11.2 \\
\hline 1 year -5 years & 41 & 22 \\
\hline 6 years -10 years & 35 & 18.7 \\
\hline More than 10 years & 90 & 48.1 \\
\hline Total & 187 & 100.0 \\
\hline \multicolumn{3}{|l|}{ Support from immediate supervisor } \\
\hline Very low & 18 & 9.6 \\
\hline Low & 17 & 9.1 \\
\hline Moderate & 65 & 34.8 \\
\hline High & 63 & 33.7 \\
\hline Very high & 24 & 12.8 \\
\hline Total & 187 & 100.0 \\
\hline
\end{tabular}

the National Health Insurance Fund (NHIF); the majority of respondents felt that this insurance cover was inadequate in meeting their health expenditure.
TABLE 3: Univariate analysis of enabling factors that influence health behaviour.

\begin{tabular}{lcc}
\hline Characteristics & $\begin{array}{c}\text { Frequency } \\
(n)\end{array}$ & Percent \\
\hline Preferred treatment source & & \\
$\quad$ Public facility & 97 & 51.9 \\
Private facility & 85 & 45.4 \\
Self-treatment & 5 & 2.7 \\
Total & 187 & 100.0 \\
Insurance cover possessed by nurses & & \\
NHIF & 180 & 96.3 \\
UAP & 2 & 1.1 \\
Jubilee & 4 & 2.1 \\
CIC & 1 & .5 \\
Total & 187 & 100.0 \\
Satisfaction with the adequacy of & & \\
insurance cover & & \\
No & 103 & 55.1 \\
Yes & 84 & 44.9 \\
Total & 187 & 100.0
\end{tabular}

Number of hours that nurses in Kakamega County spend working per week

$\begin{array}{lcc}\text { Less than } 40 \text { hours } & 7 & 3.7 \\ 40-50 \text { hours } & 124 & 66.3 \\ \text { More than } 50 \text { hours } & 56 & 30 \\ \text { Total } & 187 & 100.0\end{array}$

Work load of nurses in Kakamega

County

$\begin{array}{lcc}\text { Low } & 1 & 0.5 \\ \text { Moderate } & 17 & 9.1 \\ \text { High } & 52 & 27.8 \\ \text { Very high } & 117 & 62.6 \\ \text { Total } & 187 & 100.0\end{array}$

Satisfaction with the health services that you have access to in this county

$\begin{array}{lcc}\text { No } & 153 & 83.1 \\ \text { Yes } & 31 & 16.9 \\ \text { Total } & 184 & 100\end{array}$

Satisfied with the quality of health services that are available to you

\begin{tabular}{lcc} 
No & 145 & 78.8 \\
Yes & 39 & 21.2 \\
Total & 184 & 100.0 \\
\hline
\end{tabular}

5.3. Need Factors Influencing Health Behaviour. As Table 4 shows, the majority, $44.9 \%(n=84)$, rated their current health at the time of study as good and as being about the same state as compared to a year prior to the study. Regarding how nurses rated their physical and psychological health in comparison with that of other individuals of the same age and gender, the majority rated it as better. $34.2 \%$ of the nurses were 
TABLE 4: Univariate analysis of need factors that influence health behaviour.

\begin{tabular}{lcc}
\hline Characteristics & $\begin{array}{c}\text { Frequency } \\
(n)\end{array}$ & Percent \\
\hline Rating current health & & \\
Poor & 4 & 2.1 \\
Fair & 58 & 31.0 \\
Good & 84 & 44.9 \\
Very good & 25 & 13.4 \\
Excellent & 16 & 8.6 \\
Total & 187 & 100.0
\end{tabular}

Rating of nurses' general heath in comparison to last year

Worse
Fairer
About the sam
Good
Very good
Total

Rating nurses' comparison of their physical health with that of other individuals of the same age and gender

Much worse than theirs
Somewhat worse than theirs
About the same as theirs
Better than theirs
Much better than theirs
Total

Rating nurses' comparison of their psychological health with that of other individuals of the same age and gender

Much worse than theirs

Somewhat worse than theirs

About the same as theirs

Better than theirs

Much better than theirs

Total

Rating nurses health concerns

about their health in the preceding 12 months.

\begin{tabular}{lcc} 
Not concerned at all & 23 & 12.3 \\
Slightly concerned & 24 & 12.8 \\
Somewhat concerned & 29 & 15.5 \\
Moderately concerned & 47 & 25.1 \\
Extremely concerned & 64 & 34.2 \\
Total & 187 & 100.0 \\
Rating how nurses projected their & & \\
Woalth in 2 years after the study & & \\
Fairer & 14 & 7.5 \\
About the same & 19 & 10.2 \\
Good & 29 & 15.5 \\
Very good & 65 & 34.8 \\
Total & 60 & 32.1 \\
& 187 & 100.0 \\
\hline
\end{tabular}

2.7
9.6
34.8
37.4
15.5
100.0

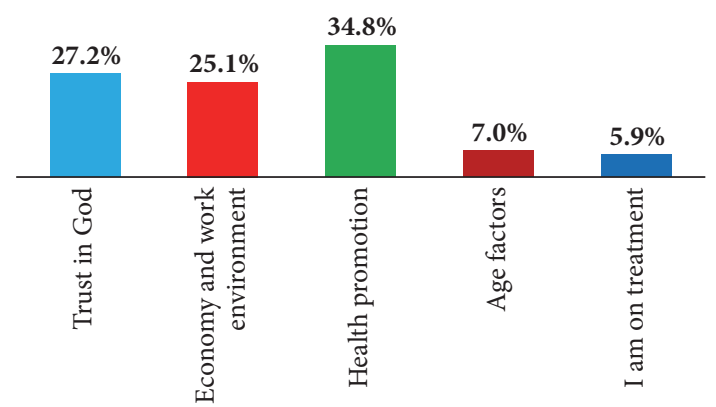

FIGURE 1: Factors that will influence nurses' health outlook in 2 years.

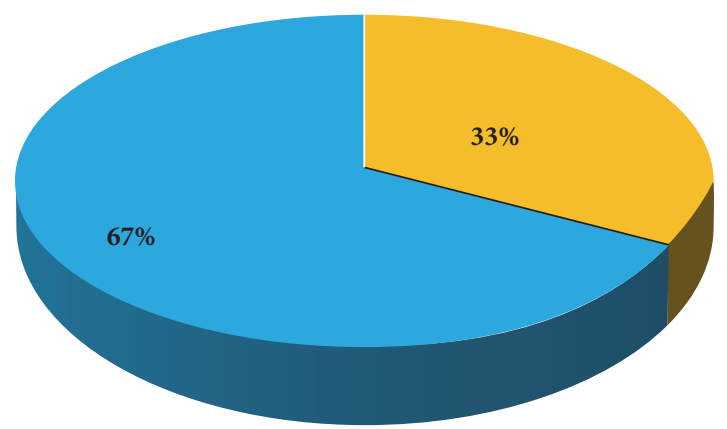

Undertook screening test

Did not undertake any screening test

FIGURE 2: Uptake of voluntary screening services by nurses.

extremely concerned about their health within 12 months preceding the study and were optimistic that their health would be good in 2 years from the time of study.

Asked for the reason as to why they said their health would be as forecasted, Figure 1 shows the reasons for the projection. Those who did not have positive prospects about the future outlook of their health cited age-related factors and poor economic returns for the future as barriers to achieving their ideal health status.

5.4. Health Behaviour of the Nurses. Health behaviour investigated self-reported voluntary actions of the respondents aimed at detecting or preventing disease and improving wellbeing. This outcome variable investigated if nurses engaged in voluntary screening services for the purpose of detecting disease.

5.5. Voluntary Screening Undertaken by the Nurses. With regard to voluntary screening services independent of a request from a health provider in the last 12 months, Figure 2 shows that $67 \%$ had never undertaken any voluntary screening service in the year preceding the study. Of these, the majority, $65.6 \%(n=40)$, were females, while $34.5 \%(n=21)$ were males.

5.6. Bivariate Analysis. The chi-square test was used to show if there existed significant differences between predisposing, need, and enabling factors to health behaviour as shown in 
TABLE 5: Cross-tabulation of predisposing, enabling, and need factors and health behaviour.

\begin{tabular}{|c|c|c|c|c|c|c|}
\hline \multirow{2}{*}{ Factors } & \multicolumn{6}{|c|}{ Health behaviour (voluntary screening uptake) } \\
\hline & \multicolumn{2}{|c|}{ Yes } & \multicolumn{2}{|c|}{ No } & \multirow[t]{2}{*}{$n$} & \multirow{2}{*}{$p=\leq 0.05$} \\
\hline \multicolumn{5}{|l|}{ Gender } & & \\
\hline Male & 21 & 34.4 & 43 & 34.1 & 64 & \multirow{3}{*}{$\begin{array}{c}\chi^{2}=0.002 \\
\mathrm{df}=1 \\
p=0.968\end{array}$} \\
\hline Female & 40 & 65.6 & 83 & 65.9 & 123 & \\
\hline$n$ & 61 & 100 & 126 & 100 & 187 & \\
\hline \multicolumn{7}{|l|}{ Age } \\
\hline$<30$ years & 9 & 14.8 & 15 & 11.9 & 24 & \multirow{5}{*}{$\begin{aligned} \chi^{2} & =2.113 \\
\mathrm{df} & =3 \\
p & =0.549\end{aligned}$} \\
\hline $30-39$ years & 16 & 26.2 & 39 & 31.0 & 55 & \\
\hline $40-49$ years & 21 & 34.4 & 33 & 26.2 & 54 & \\
\hline$>50$ years & 15 & 24.6 & 39 & 31.0 & 54 & \\
\hline$n$ & 61 & 100 & 126 & 100 & 187 & \\
\hline \multicolumn{7}{|l|}{ Marital status } \\
\hline Married & 42 & 68.9 & 101 & 80.2 & 143 & \multirow{3}{*}{$\begin{array}{c}\chi^{2}=2.920 \\
\mathrm{df}=1 \\
p=0.087\end{array}$} \\
\hline Otherwise & 19 & 31.1 & 25 & 19.8 & 44 & \\
\hline$n$ & 61 & 100 & 126 & 100 & 187 & \\
\hline \multicolumn{7}{|l|}{ Religion } \\
\hline Protestant & 44 & 79.3 & 103 & 77.5 & 147 & \multirow{4}{*}{$\begin{array}{c}\chi^{2}=2.920 \\
\mathrm{df}=1 \\
p=0.133\end{array}$} \\
\hline Catholic/muslim & 17 & 20.7 & 23 & 22.5 & 40 & \\
\hline$n$ & 61 & 100 & 126 & 100 & 187 & \\
\hline Highest level of training as a nurse & & & & & & \\
\hline $\mathrm{BScN} /$ higher dip./postgraduate & 17 & 27.9 & 27 & 21.4 & 44 & \multirow{4}{*}{$\begin{array}{c}\chi^{2}=0.947 \\
\mathrm{df}=1 \\
p=0.330\end{array}$} \\
\hline Diploma and below & 44 & 72.1 & 99 & 78.6 & 143 & \\
\hline$n$ & 61 & 100 & 126 & 100 & 187 & \\
\hline \multicolumn{6}{|l|}{ Time working as a nurse } & \\
\hline 6 months -5 years & 23 & 37.7 & 39 & 31.0 & 62 & \multirow{3}{*}{$\begin{array}{c}\chi^{2}=0.846 \\
\mathrm{df}=1 \\
p=0.358\end{array}$} \\
\hline Above 5 years & 38 & 62.3 & 87 & 69.0 & 125 & \\
\hline$n$ & 61 & 100 & 126 & 100 & 187 & \\
\hline \multicolumn{7}{|l|}{ Support from supervisor } \\
\hline Low & 27 & 44.3 & 64 & 50.8 & 91 & \multirow{3}{*}{$\begin{array}{c}\chi^{2}=0.702 \\
\mathrm{df}=1 \\
p=0.402\end{array}$} \\
\hline High & 34 & 55.7 & 62 & 49.2 & 96 & \\
\hline$n$ & 61 & 100 & 126 & 100 & 187 & \\
\hline \multicolumn{7}{|l|}{ Worried about future health } \\
\hline Worried & 42 & 68.9 & 66 & 52.4 & 108 & \multirow{3}{*}{$\begin{array}{c}\chi^{2}=4.570 \\
\mathrm{df}=1 \\
p=0.033\end{array}$} \\
\hline Not worried & 19 & 31.1 & 60 & 47.6 & 79 & \\
\hline$n$ & 61 & 100 & 126 & 100 & 187 & \\
\hline
\end{tabular}

Table 5 . The only variable that was statistically significant was the nurses' concerns about the future prospects. The finding shows, though without significance difference, that being female, increasing age, being married, being a Protestant, having diploma qualification, having longer working experience, good supervisor support, and being worried about future health positively influence health behaviour.

5.7. Types of Voluntary Screening Services Undertaken by Nurses. The most prevalent voluntary screening services reported to have been undertaken included HIV screening, cervical cancer screening, breast cancer screening, diabetes screening, and screening for hypertension. All the respondents reported to have undertaken multiple tests.

\section{Reasons for Undertaking Voluntary Screening Services by the Nurses}

Figure 3 shows that, for those who undertook voluntary screening services $(n=61)$, the majority $(46.0 \%)$ said they wanted to be in control of their health, $20.0 \%$ said they knew they were at risk of disease, $16.0 \%$ said they were worried about their health, and $10.0 \%$ said the test was offered for free, while $8.0 \%$ said they were concerned about their health. 

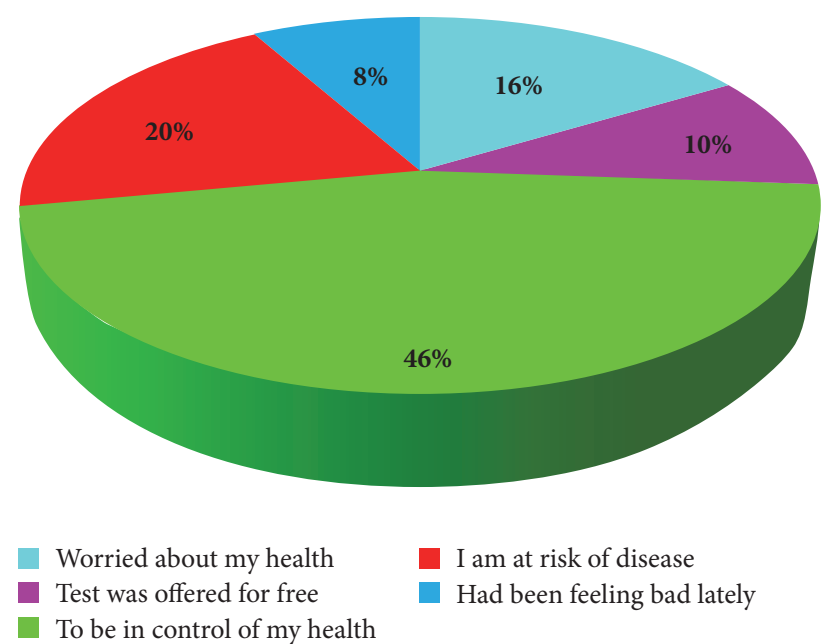

FIGURE 3: Reasons for undertaking screening tests by the nurses.

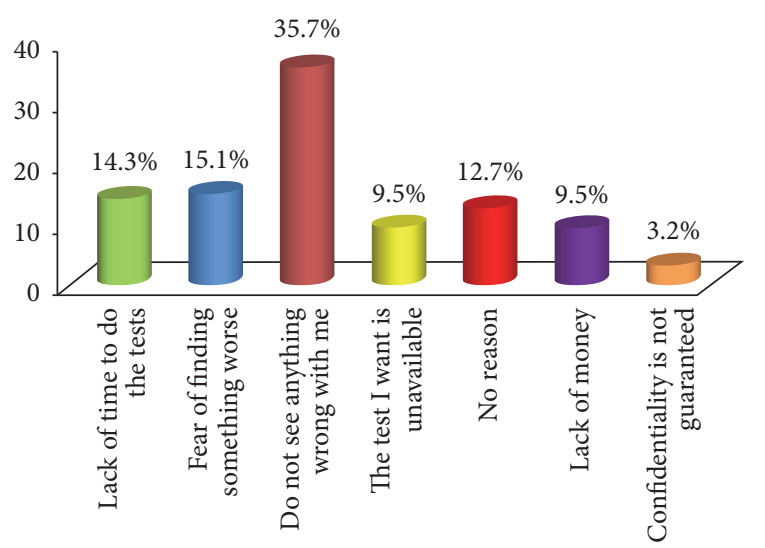

FIGURE 4: Reasons for not undertaking screening tests by the nurses.

\section{Barriers to Undertaking Voluntary Screening Services by the Nurses}

Figure 4 shows that, for those who had never undertaken any voluntary screening tests in the said period $(n=126)$, the majority $(35.7 \%)$ said they saw nothing wrong with themselves, $15.1 \%$ said they feared finding something worse, $14.3 \%$ said they lacked time to do the tests, $12.7 \%$ said they did not have a reason, and 19\% said lack of both money and the test they wanted prevented them, while $3.2 \%$ attributed it to fear for their confidentiality not being guaranteed.

7.1. Chronic Illnesses Reported by the Nurses. The majority, $70.6 \%(n=132)$, of the nurses reported that they did not suffer from any chronic illness. This was followed by $27.3 \%(n=51)$ who said they suffered from at least one chronic illness and lastly $2.1 \%(n=4)$ reported that they did not know if they suffered from any chronic illness. The prevalence of hypertension was highest at $9.1 \%(n=17)$, followed by diabetes mellitus at $2.7 \%(n=5)$ and HIV at $1.1 \%(n=2)$ among others.

\section{Discussion}

With regard to age, the majority of the nurses belonged to age bracket of 30-39 years and their mean age was 41 years. This finding is consistent with Ministry of Health's [26] report that showed that the majority of Kenyan nurses were in age bracket of 31-40 years. Similarly, Wakaba et al. [29], while investigating the public sector nursing workforce in Kenya, found the mean age of nurses to be 44 years.

The respondents who rate their health as good reported utilizing voluntary services more; this is a paradox because it is not clearly evident on the basis of this study to establish whether the good rating of health was a result of a positive screening result or whether the self-appraisal of poor health was a barrier to screening services uptake with fear of finding something worse as a real fear. Fear of finding something worse as a barrier to screening tests is well documented in literature; for example, Frank and Segura [5] found that health professionals did not undertake screening tests because of fear, while Lindo et al. [30] found the barrier to be related to confidentiality within the health profession. Another barrier to screening tests was the fact that nurses saw nothing wrong with their health. This report was common in the young, those with a higher diploma and above, and those who had worked for less than five years in the county. Despite individual differences, one expects that a profession that is the gate keeper of health should be in the frontline not only advocating for but also undertaking screening tests knowing that they are at risk of disease, but that is contrary. This can be attributed to the fact that nurses feel invincible and believe that illness belongs to patients. Although nursing is a calling to serve humanity, not actively taking the lead in engaging in health preventive behaviour and leaving the future health prospect to "the will of God" is in itself a barrier that nurses in Kakamega County must overcome in the pathway to personal health locus of control because the realisation of vision 2030 is hinged on health [31], which must first start with that of the caregivers, the nurses.

Regarding the prevalence of life-limiting illness, the majority reported suffering from hypertension, followed by those who suffer from diabetes, with $0.5 \%$ of the respondents volunteering their HIV-positive status. It is worthwhile to note that whereas the majority of the nurses had never undertaken a screening test, they reported having no chronic disease, an interesting finding that could corroborate invincibility. The finding is consistent with that of Canbulat and Uzun [32] who found that the screening practices of health workers were low, which contributed to the perceived low levels of life-limiting illnesses in health workers. The low level of screening tests undertaken accrues from the fact that the majority of the respondents see nothing wrong with themselves and therefore have not undertaken screening tests, yet it is known that life-limiting illnesses in their infancy are asymptomatic. Peleg et al. [18] found that doctors had strong beliefs in screening tests but these beliefs did not translate to personal uptake. The fear, invincibility, and the belief that the nurses are the barometer for public's health status are misleading and must be addressed if nurses want to be better role models for the public. 


\section{Conclusions and Recommendations}

The study revealed high proportion of nurses that did not undertake screening services voluntarily. As nurses, it is expected that they not only teach the public about the benefits of health behaviour but also lead as example in undertaking the voluntary screening tests to detect early disease. This study has uncovered the existing barriers to uptake of screening tests among nurses. These barriers are crosscutting in the biosocioeconomic sphere of the nurses. Further, cost is an important barrier to uptake of screening services coupled with the finding that Kakamega County is not well endowed with the resources that are necessary for voluntary screening services among nurses. This study recommends that there is a need to promote health behaviour of the young and male nurses to uptake screening services more; this may mean more education. Nurses also need to be sensitized to undertake screening tests for both communicable and noncommunicable diseases not only for the purpose of leading from the front but also so that the Kakamega County population is served by a healthy work force, from which they draw inspiration. It is also important that the prioritization of scarce resources for health care in Kakamega County be addressed so that adequate resources are allocated for screening services to enable nurses to undertake screening services more.

\section{Additional Points}

Limitations of the Study. This study was cross-sectional in nature and therefore could not infer causation for any of the factors to health behaviour. The study relied on self-report, which has its inherent weakness.

Areas of Further Research. (1) Investigate health behaviour of all nurses using a nationwide sample so that there is a national reference point. (2) Investigate, through qualitative designs, the decision-making processes underlying health behaviour and barriers to health behaviour experienced by the nurses so as to uncover factors that enhance use of the reported health behaviour. (3) Investigate the determinants of access to quality health services to the nurses which can promote screening services uptake among nurses.

\section{Conflicts of Interest}

The authors declare that there are no conflicts of interest regarding the publication of this paper and that the study was fully funded by the principal investigator.

\section{References}

[1] N. Weinstein and R. M. Ryan, "When helping helps: autonomous motivation for prosocial behavior and its influence on well-being for the helper and recipient," Journal of Personality and Social Psychology, vol. 98, no. 2, pp. 222-244, 2010.

[2] K. L. Rush, C. C. Kee, and M. Rice, "The self as role model in health promotion scale: development and testing," Western Journal of Nursing Research, vol. 32, no. 6, pp. 814-832, 2010.
[3] H. Blake, S. Malik, P. K. H. Mo, and C. Pisano, 'Do as I say, but not as I do': Are next generation nurses role models for health?vol. 131, no. 5, pp. 231-239, 2011.

[4] B. Babitsch, D. Gohl, and T. von Lengerke, "Re-revisiting Andersen's Behavioral Model of Health Services Use: a systematic review of studies from 1998-2011," Psycho-social Medicine, vol. 9, 2012.

[5] E. Frank and C. Segura, "Health practices of Canadian physicians," Canadian Family Physician, vol. 55, no. 8, pp. 810-811, 2009.

[6] S. Chankova, S. Muchiri, and G. Kombe, "Health workforce attrition in the public sector in Kenya: a look at the reasons," Health workforce attrition in the public sector in Kenya: a look at the reasons, vol. 7, no. 1, p. 58, 2009.

[7] R. Collier, “The 'physician personality' and other factors in physician health," Canadian Medical Association Journal, vol. 184, no. 18, pp. 1980-1980, 2012.

[8] M. N. K. Karanikola and C. Kaite, "Greek-Cypriot mental health nurses' professional satisfaction and association with mild psychiatric symptoms: MHNs' Professional Satisfaction and Psychiatric Symptoms," International Journal of Mental Health Nursing, vol. 24, no. 4, pp. 347-358, 2013.

[9] I. Fronteira and P. Ferrinho, "Do nurses have a different physical health profile? A systematic review of experimental and observational studies on nurses' physical health: Systematic review of experimental and observational studies on nurses' physical health," Journal of Clinical Nursing, vol. 20, no. 17-18, pp. 2404-2424, 2011.

[10] S. Letvak, "We cannot ignore nurses' health anymore: A synthesis of the literature on evidence-based strategies to improve nurse health," Nursing Administration Quarterly, vol. 37, no. 4, pp. 295-308, 2013.

[11] L. P. Phiri, C. E. Draper, E. V. Lambert, and T. L. KolbeAlexander, "Nurses' lifestyle behaviours, health priorities and barriers to living a healthy lifestyle: a qualitative descriptive study," BMC Nursing, vol. 13, no. 1, p. 1, 2014.

[12] Department of Health, "Invisible patients, Report of the Working Group on the health of health professionals," 2010.

[13] S. Judkins, "Hardiness, job satisfaction, and stress among home health nurses," Home Health Care Management Practice, vol. 17, no. 2, pp. 113-118, 2005.

[14] L. D. Wolf, P. Potter, J. A. Sledge, S. B. Boxerman, D. Grayson, and B. Evanoff, "Describing Nurses Work: Combining Quantitative and Qualitative Analysis," The Journal of the Human Factors and Ergonomics Society, vol. 48, no. 1, pp. 5-14, 2006.

[15] P. A. Agaba, A. N. Ocheke, M. O. Akanbi et al., "Health seeking behavior of physicians at the Jos University Teaching Hospital," Nigerian Medical Journal, vol. 52, no. 2, p. 90, 2011.

[16] Anonymous, "Medicine and mental illness: how can the obstacles sick doctors face be overcome?" The Psychiatrist, vol. 36, no. 3, pp. 104-107, 2012.

[17] A. Tuckett, P. Winters-Chang, F. Bogossian, and M. Wood, "Why nurses are leaving the profession ... lack of support from managers": What nurses from an e-cohort study said: Leaving the profession: What nurses said," International Journal of Nursing Practice, vol. 21, no. 4, pp. 359-366, 2015.

[18] R. Peleg, A. Ostermich, V. Gienco, and E. Portughiez, "Screening tests among family doctors: do we do as we preach?" Public Health, vol. 127, no. 3, pp. 282-289, 2013.

[19] E.-S. Nahm, J. Warren, S. Zhu, M. An, and J. Brown, "Nurses' self-care behaviors related to weight and stress," Nursing Outlook, vol. 60, no. 5, pp. e23-e31, 2012. 
[20] J. E. Wallace, J. B. Lemaire, and W. A. Ghali, "Physician wellness: a missing quality indicator," The Lancet, vol. 374, no. 9702, pp. 1714-1721, 2009.

[21] A. I. Garelick, "Doctors' health: Stigma and the professional discomfort in seeking help," Psychiatrist, vol. 36, no. 3, pp. 8184, 2012.

[22] C. Figley, P. Huggard, and C. Rees, First do no self harm: Understanding and promoting physician stress resilience, Oxford University Press, Oxford, UK, 2013.

[23] F. Fox, M. Harris, G. Taylor et al., "What happens when doctors are patients? Qualitative study of GPs," British Journal of General Practice, vol. 59, no. 568, pp. 811-818, 2009.

[24] M. Kay and A. Clavarino, "Doctors as patients: a systematic review of doctors' health access and the barriers they experience," British Journal of General Practice, vol. 58, no. 552, pp. 501-508, 2008.

[25] M. Taegtmeyer, R. M. Suckling, P. M. Nguku et al., "Working with risk: Occupational safety issues among healthcare workers in Kenya," AIDS Care Psychological and Socio-medical Aspects of AIDS/HIV, vol. 20, no. 3, pp. 304-310, 2008.

[26] Ministry of health, "Kenya Nursing Workforce Report: The Status of Nursing in Kenya, 2012.

[27] J. Y. Chen, E. Y. Tse, T. P. Lam, D. K. Li, D. V. Chao, and C. W. Kwan, "Doctors personal health care choices: a crosssectional survey in a mixed public/private setting," in Doctors' personal health care choices: a cross-sectional survey in a mixed public/private setting, vol. 8, p. 183, BMC Public Health, 2008.

[28] I. McDowell, Measuring health: a guide to rating scales and questionnaires, Oxford University Press, New York, NY, USA, 3rd edition, 2006.

[29] M. Wakaba, P. Mbindyo, J. Ochieng et al., "The public sector nursing workforce in Kenya: A county-level analysis," Human Resources for Health, vol. 12, no. 1, article no. 6, 2014.

[30] J. L. Lindo, J. LaGrenade, A. McCaw-Binns, and D. EldemireShearer, "Health status and health maintenance practices among doctors and nurses at two hospitals in Jamaica," The West Indian medical journal, vol. 58, no. 6, pp. 539-545, 2009.

[31] Kenya economic report, Creating an enabling environment for stimulating investment for competitive and sustainable counties, Kenya Institute for Public Policy Research and Analysis, Nairobi, Kenya, 2013.

[32] N. Canbulat and Ö. Uzun, "Health beliefs and breast cancer screening behaviors among female health workers in Turkey," European Journal of Oncology Nursing, vol. 12, no. 2, 2008. 


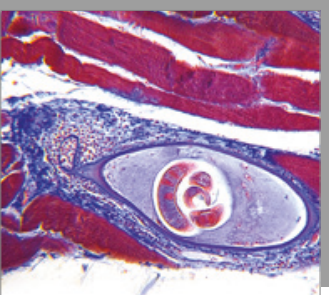

Gastroenterology

Research and Practice
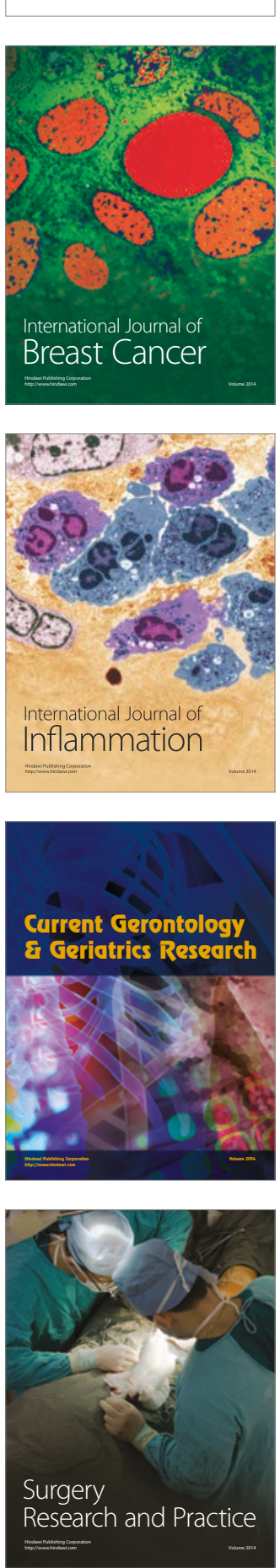

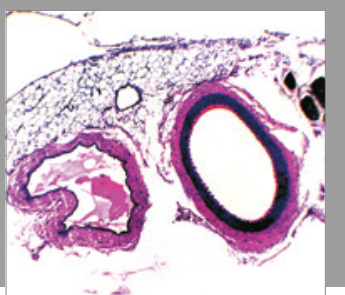

International Journal of Hypertension
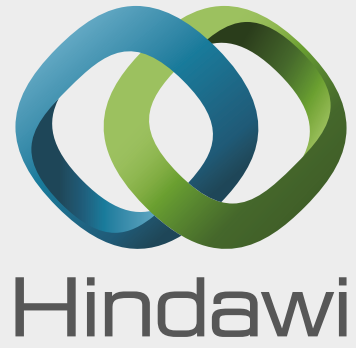

Submit your manuscripts at

https://www.hindawi.com

\section{The Scientific Nursing}

World Journal

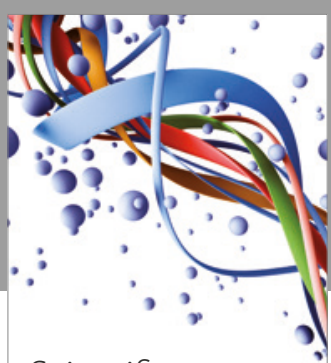

Scientifica

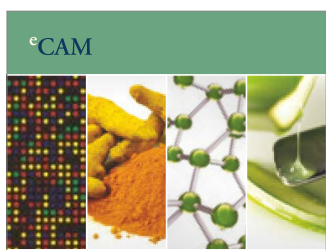

Evidence-Based

Complementary and

Alternative Medicine
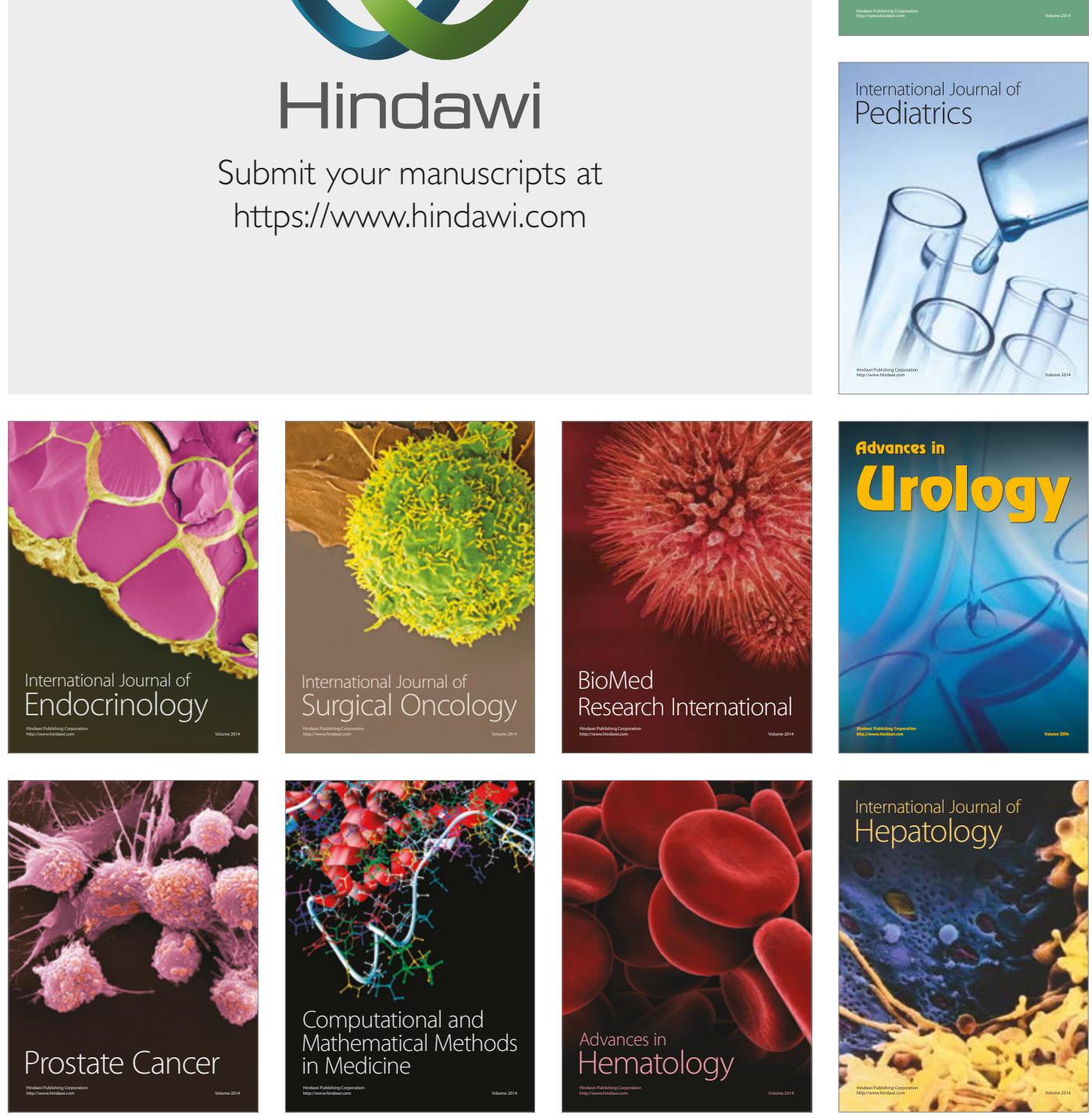